Book Review

ISSN: 2162-3104 Print/ ISSN: 2166-3750 Online

Volume 6, Issue 4 (2016), pp. 1076-1078

(C) Journal of International Students

http://jistudents.org/

\title{
International Student Engagement: Strategies for Creating Inclusive, Connected, and Purposeful Campus Environments
}

Glass , C. R., Wongtrirat , R., \& Buus , S. (2014). International Student Engagement: Strategies for Creating Inclusive, Connected, and Purposeful Campus Environments. Sterling, VA: Stylus.

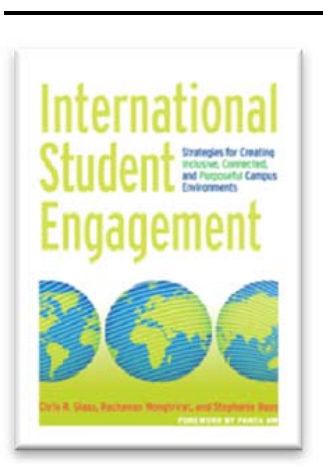

Reviewed by Clyde Barnett III, Eastern Michigan
University (USA)

International Student Engagement: Strategies for Creating Inclusive, Connected, and Purposeful Campus Environments is an in-depth analysis of seven colleges and universities across the United States, examining unique programs and activities for international students that foster belonging and connectedness on campus. This book provides a snapshot into the ways institutions effectively engage with international students. The authors examine the effectiveness of programs and policies intended to assist international students through research findings and by examining first-hand student experiences. For higher education/student affairs professionals, this book is an excellent resource to help move higher education institutions forward and into a space that promotes inclusivity.

The authors of this book examined practices at Elon University, Florida International University, Indiana University-Bloomington, Northern Arizona University, Old Dominion University, Valencia College, and Valparaiso University. These institutions, selected because of their commitment and effort to strengthen inclusion of international students, each represent varying missions, values, histories, and traditions. Key areas of focus include strengthening cross-campus connections, exploring ways to deepen the quality of international student experience, and expanding the number of students actively engaged in intercultural learning. From multiple in-depth interviews, the authors highlighted successes as well as struggles international students faced when navigating campus culture. These 
interviews also bring light to the negative impacts of overlooking international students and their experiences and remind us that not all experiences impact international students equally.

The first section of the book analyzes how cultural diversity is addressed in the classroom. The research identified that international students adjust better in dialogue-filled courses rather than traditional lecture style courses. Efforts from faculty that display a deep understanding and commitment to embracing cultural variation in the classroom really enhance student learning and simultaneously challenge domestic students to think and reflect about the way they view and exist in the world. Intentionally designed classrooms can provide a safe haven from, or a much-needed complement to, the formal chaotic, and complex social cultures outside of the classroom. The opportunity to engage in dialogue, discussion, and interaction with peers in the classroom assists in forming the core of international students' understanding of U.S. peers and the world at large. Enhancing classroom experience for international students requires a comprehensive approach in which global learning is deliberate, connected, and pervasive across the student experience.

Chapter 2 focuses on engaging international students in campus leadership. Involving international students and perspectives into campus leadership in purposeful ways helps students make sense of their experiences studying in the United States. Further, involvement in leadership programs bridges gaps and establishes campus connections between otherwise distantly connected people. This also enhances the students desire to engage on campus both inside and outside of the classroom and creates a sense of belonging. Many of these campuses work to involve all students in service learning projects in the institutions surrounding communities, all things that significantly impact engagement within campus life. Movement away from cultural traditions into spaces needing navigation improves self-understanding within the framework of resilience and agency despite frustration with acclimation into American culture and norms.

In Chapter 3, friends, peers, and social networks are examined and provide practitioners with further context into how domestic and international students engage. As it stands, international students trade strong familial ties at home for weaker and very simple connections with US peers and community. Because of this, some students describe their time studying in the United States as being a "tourist on an extended trip." First hand accounts of student experiences are detailed throughout and shed light on the identity struggle many international students encounter.

The next chapter transitions into the roles of family, relationships, technology, and social media. Colleges and universities in the United States must be prepared to approach international students both as individuals and 
representatives of their extended family networks. For many international students, obtaining an education is not only for self-advancement, but to support family back home for various reasons, ranging from cultural considerations to financial support. Obtaining an education in the US is expected to result in tangible benefits for the entire family. Without family and extended family support, international study would not be possible for international students. The use of social media is viewed more as a ritual to maintain cultural and personal connections rather than simply an online social activity. Here authors also outline the practices of Indiana UniversityBloomington (IU), a trailblazer in international student engagement, on their approach to purposeful cross-campus dialogue in regards to building and sustaining positive relationships.

Chapter 5 dives deeper into fostering belonging for international students on US college campuses. The authors call for higher education administrators and faculty to no longer turn a blind eye to the fundamental role that belonging plays in human life. This involves a change from focusing on vulnerabilities toward a more holistic and constructive focus on resilience and strength. Further, it is recommended that a shift occur from international students as relatively unconnected, autonomous individuals to a focus on international students as participants in complex and influential social networks. Lastly, authors advocate evolving from the traditional focus on professionalized student services toward a self-authorship model.

Recommendations, implications for practice, and opportunities for potential modeling are made throughout this book. The final chapter provides comprehensive recommendations for practice for faculty and staff at US higher education institutions to better support students from all backgrounds. The authors also acknowledge challenges this presents as universities have competing priorities. Lastly, details on effective campus partnerships and faculty engagement are outlined.

The authors of this book provide a collection of research that successfully conveys many issues that international students face on US college campuses. The personal accounts, review of leading programs, and recommendations of good practice in this book challenge individuals and institutions to truly understand the experiences of international students and the types of environments being cultivated. Higher education institutions must continue to improve inclusion efforts for international learners on campus by providing superior campus support services from actively engaged, committed, and passionate faculty and staff.

CLYDE BARNETT III is a graduate student in Educational Leadership at Eastern Michigan University. His email is cbarnet5@emich.edu. 